Anuario da Facultade de Dereito da Universidade da Coruña

Vol. 21 (2017), pp. 401-422

ISSNe: 2530-6324 || ISSN: 1138-039X

DOI: https://doi.org/10.17979/afdudc.2017.21.0.3288

\title{
FONDEVILA MARÓN, M., La reforma constitucional en España. Un ensayo de derecho constitucional como ciencia teórico-práctica, Andavira, Santiago de Compostela, 2016, 224 págs.
}

\author{
Manuel Cabanas Veiga \\ Doctorando en Derecho constitucional \\ Universidad de A Coruña
}

\section{INTRODUCCIÓN}

Habiendo tenido el honor de disponer de uno de los ejemplares dela nueva obra de mi colega, Manuel Fondevila marón, y tras leerla con detenimiento y suma atención, surgió la imperiosa necesidad de llevar a cabo un estudio pormenorizado del total de su actual obra, a la vista de la elocuencia de la misma. Este libro es una continuación del legado del Grupo Tierno, trasmitida por Pedro de Vega a nuestro Maestro común, Javier Ruipérez Alamillo, al cual le debemos el placer de recibir tan valioso legado. Y como temática indispensable en toda obra que persiga considerarse continuadora del mismo, aborda inevitablemente la importancia de la Democracia como forma de gobierno. Se trata de partir, como todos debería ser ya conocido, del principio democrático como criterio evaluador desde el cual medir la conveniencia de las instituciones políticas. Por ello, la obra de este joven jurista se centra en la idea de presentar la reforma constitucional, al igual que lo hizo Pedro de Vega, como la mejor forma de defender la Democracia y, con ella, la Constitución, frente aquellos ataques que cuestionan su legitimidad.

Y lo hace a la vista de que, en la actualidad, se ha abierto un debate en todas las fuerzas políticas españolas en torno a la necesidad de reformar la Constitución. Sin embargo, este paso desde la tradicional mentalidad de la clase política y doctrinal del 
temor a la reforma, vista como una forma subrepticia de deslealtad constitucional, al consenso general a reformar cualquier parte de la Constitución, siguiendo el procedimiento que sea, ha hecho pasar, para el miope político, al Grupo Tierno, de la noche a la mañana, más concretamente, desde la precampaña electoral del 2011, de posiciones consideradas revolucionarias al conservadurismo más rancio. Así, al igual que aquel viejo socialista que, con la entrada del neoliberalismo, pasó de ser perseguido por "rojo" y "revolucionario", en España, a ser considerado "marginal" y "obsoleto", las ideas del Grupo Tierno también pasaron, o al menos eso se quiere hacer creer, en un corto periodo de tiempo, de revolucionarias a conservadoras.

Sin embargo, las premisas siguen siendo las mismas que las sostenidas por aquel simpático alcalde, amado por todas las generaciones de una misma época, que defendía en un concierto celebrado en la ciudad que regía, Madrid, que "quien no esté colocado, que se coloque". El problema procede, sin embargo, de la confusión, tanto teórica como práctica, de gran parte de la doctrina y la clase política española, entre el Poder Constituyente y el Poder de Reforma, que el autor, al que analizamos, pretende poner de manifiesto para que se busque una solución. Y es que, como sostiene Fondevila, se ha pasado del rechazo absoluto a la reforma constitucional ${ }^{1}$, pensando que a través de la misma se podría establecer otro régimen político diferente, con fórmulas tan famosas como "que se rompe España" o tan arcaicas como "que vienen los rojos", a considerar que todo puede ser objeto de las fauces de los comités de partido, si sus representantes cuentan con las mayorías agravadas necesarias. De este modo, en un lapso reducido de tiempo, se ha pasado del temor a la reforma a la reforma descontrolada.

Ahora bien, lo que realmente ha sucedido es que el conservadurismo sigue siendo el mismo, sólo que con posiciones diferentes ante los acontecimientos. Antes se oponían a la reforma por el miedo a la revolución y ahora buscan hacer la revolución ellos mismos. Por dicha razón, Fondevila pone claramente de manifiesto cómo, desde el principio democrático, el Pueblo es el único legitimado para alterar la Constitución, por lo que los gobernantes no tienen potestad ni para impedirle darse una nueva Constitución ni para su actualización ${ }^{2}$, como tampoco la tienen para suplantarlo en sus funciones soberanas y establecer el documento de gobierno de un Estado al margen o, incluso, en contra, de la voluntad del Pueblo ${ }^{3}$. Por ello, uno de los temas que aborda es la nítida separación entre el Poder Constituyente y el Poder de reforma constitucional como supuesto elemental para perpetuar el régimen democrático en un Estado ${ }^{4}$. Y ello lo hace defendiendo los siempre tan polémicos pero necesarios límites materiales, es

\footnotetext{
${ }^{1}$ Ibídem, pp. 19-21 y 98-99.

${ }^{2}$ Ibídem, p. 32.

${ }^{3}$ Cfr., RUIPÉREZ AlAMILlO, J., La Constitución del Estado de las Autonomías. Teoría constitucional y práctica política en el "federalising process" español, Ed. Biblioteca Nueva S. L., Madrid, 2003, p. 147, RUIPÉREZ ALAMILlO, J., Reforma vs. Revolución. Consideraciones desde la Teoría del Estado y de la Constitución sobre los límites materiales a la revisión constitucional, Porrúa, México, 2013, pp. 34-35 y FONDEVILA MARÓN, M., "Derecho a decidir y soberanía. A propósito de la STC 42, 2014, de 25 de marzo", TRC., núm. 34, 2014, p. 605.

${ }^{4}$ Cfr., RUIPÉREZ ALAMILLO, J., Reforma vs. Revolución. Consideraciones desde la Teoría del Estado y de la Constitución sobre los límites materiales a la revisión constitucional, Porrúa, México, 2013, p. 125.
} 
decir, aquellos principios y valores vedados al Poder de reforma constitucional ${ }^{5}$. Además, consideramos, al igual que Fondevila, que es un error rechazar la existencia de límites materiales en nuestra Constitución porque la misma haya optado por un modelo de democracia no militante, ya que las cláusulas de intangibilidad no buscan defender la democracia, sino mantener la identidad de la Constitución. No son un medio de defensa de la democracia a través de la Constitución, sino que son un complemento; pero no forman parte de la democracia militante ${ }^{6}$. Estos se convierten, de esta manera, en el muro de contención de aquellos poderes que buscan sobrepasar sus poderes más allá de su legitimidad.

Pero la reforma constitucional que abrió la puerta a futuros poderes de reforma, con las posturas del "todo se puede reformar y de cualquier manera" ha sido la del 2011, con la reforma del art. 135 de nuestra Constitución. A través de la misma, como con acierto enuncia el autor, se lleva a cabo la modificación del art. 135 mediante el procedimiento ordinario de reforma, es decir, el del art. 167, a pesar de que con la misma se estaba llevando a cabo la reforma subrepticia de una parte esencial del art. 1 de la Constitución $^{7}$, concretamente, el Estado social, para cuya modificación sería preciso llevar a cabo, al menos desde el punto de vista formal, el procedimiento establecido en el art. 168. Sin embargo, por ser la forma política del Estado un límite implícito a la reforma constitucional, en el cual se incluye el Estado social, aunque el autor no lo mencione expresamente ${ }^{8}$, ninguno de los dos procedimientos de reforma constitucional establecido por nuestro Constituyente es legítimo, ya que ello supondría admitir que un poder constituido, como es el poder de reforma, pueda asumir competencias soberanas. Claro que quienes defienden dicha reforma constitucional, niegan con rotundidad esa afectación. Y esta fue la razón esgrimida por nuestro Tribunal Constitucional, quien mediante auto decidió despachar de forma liminar el asunto ${ }^{9}$, estableciendo la improcedencia del recurso, lo cual también critica el autor en su libro.

\section{PRESENTACIÓN DE LA OBRA.}

Partiendo de estas consideraciones, llevará a cabo un interesante análisis histórico de los procedimientos de reforma de los diferentes textos de nuestro constitucionalismo histórico, lo que le permitirá diferenciar entre las verdaderas Constituciones y aquellas que sólo sirvieron de instrumentos de gobierno a quien se encontrase en ese momento en el poder. Así, una de las importantes aportaciones de esta obra es el repaso histórico de los procedimientos de reforma de los diferentes textos constitucionales españoles, haciendo hincapié en como dicha separación de poderes es fundamental para poder

\footnotetext{
${ }^{5}$ Cfr., FONDEVILA MARÓN, M., "Los límites a la reforma de la Constitución", AFDUC, 2015, pp. 252-254 y RUIPÉREZ ALAMILLO, J., Reforma vs. Revolución. Consideraciones desde la Teoría del Estado y de la Constitución sobre los límites materiales a la revisión constitucional, Porrúa, México, 2013, pp. 73-95.

${ }^{6}$ Cfr., FONDEVILA MARÓN, M., La reforma constitucional en España ..., pp. 115-117.

${ }^{7}$ Ibídem, pp. 120-123.

${ }^{8}$ Ibídem, p. 77.

${ }^{9}$ Auto 9/2012 del Tribunal Constitucional español por el que se inadmite el recurso de amparo contra el procedimiento de la reforma constitucional.
} 
diferenciar entre constituciones semánticas y verdaderas Constituciones. Desde esta perspectiva, Fondevila lleva a cabo un estudio de la Constitución de la II República española y de las Leyes Fundamentales del Reino franquistas y de sus respectivos procedimientos de reforma para acentuar la diferencia entre un sistema autoritario, donde el Poder Constituyente y el Poder de reforma constitucional confluyen en un mismo poder, y un sistema democrático, donde existe una nítida separación entre los mismos. Además, derivada de la situación del régimen de Franco, se rechazará cualquier plasmación constitucional de cláusulas de intangibilidad debido a que las mismas recordaban a las Leyes Fundamentales del Reino. Sin embargo, lejos de contribuir ello a fortalecer la democracia, puede ponerla en riesgo.

De esta forma, a continuación, pasará a examinar la reforma constitucional de la Constitución de 1978. A través de dicho análisis denunciará la incoherencia de mantener dos procedimientos de reforma en atención a preceptos y no tanto a materias, llevando a confundir el Poder de reforma con el Poder Constituyente e impidiendo, de este modo, la adaptación de nuestra Carta Magna a la realidad jurídica, política y social española. También se pondrá de manifiesto la errónea decisión de excluir al Pueblo del procedimiento de reforma constitucional, tanto en su iniciativa -por lo que el único procedimiento en el que puede intervenir como tal es mediante la revolución- como para la ratificación de la Constitución, aunque la misma no es necesaria para su aprobación, sino que sirve como medio de control frente a los posibles déficits representativos por parte de los partidos políticos en su labor como Poder de reforma constitucional.

Sin embargo, y sin duda alguno aquí se encuentra uno de los mayores pluses de esta obra, el autor no restringe su análisis a una mera formulación teórica de los problemas fundamentales de la reforma constitucional en España, como puntos de partida de cualquier investigación constitucional seria, sino que, además, recalca la necesidad de proceder a la reforma constitucional de algunos capítulos de la Constitución, las diferentes posibilidades constitucionales de llevar a cabo la reforma de cada uno de ellos y sus principales consecuencias, sin entrar a precisar, como es obvio, el tenor literal de los mismos. Así, Fondevila va a defender en dicha obra la necesidad de reforma la Constitución española de 1978 en lo relativo a la integración europea, a los derechos fundamentales, al senado, al modelo territorial del Estado, al sistema electoral, a la corona y al propio procedimiento de reforma. Además, en un apartado anterior, va a defender la reforma del art. 13.2 de la Constitución para permitir a los extranjeros no comunitarios participar en las elecciones locales y eliminar la necesidad de reciprocidad, por ser España un país de inmigración ${ }^{10}$. Sin embargo, convendría no alterar lo relativo a la reciprocidad, pues en el futuro pueden cambiar las circunstancias que conduzcan a una coyuntura internacional de emigración española masiva, ya que en los últimos años ha aumentado considerablemente.

De este modo, cuando defiende llevar a cabo una reforma constitucional en lo relativo a la integración europea, no lo hace bajo la premisa de que exista en la actualidad una

\footnotetext{
${ }^{10}$ Ibídem, p. 105 y La disolución de la soberanía en el ámbito estatal. El proceso de integración europea. Prolegómenos al estudio de Javier Ruipérez Alamillo, REUS, Madrid, 2014, pp. 141-142.
} 
contradicción entre la misma y la Constitución, ya que parte, al igual que nosotros, de que nos encontramos ante una mutación constitucional deseada por el mismo texto constitucional $^{11}$. Por ello, si defiende dicha reforma es para dotar a la Norma Suprema de mayor claridad. También sostiene que el modelo territorial español debería dilucidar constitucionalmente las competencias que tiene atribuidas el Estado y las CCAA, estableciendo mecanismos en aquellos casos en que los entes territoriales incumplan sus obligaciones competenciales y que puedan acarrear responsabilidad internacional para el Estado ${ }^{12}$. En relación al senado, comparto la idea con el autor de que el mismo no es un elemento indispensable del modelo de Estado federal ${ }^{13}$, aunque no sería conveniente eliminarlo en España, sino reformarlo, para que cumpliese una verdadera representación territorial ${ }^{14}$. Así, en cuanto a la representación, se opone a que se reforme para crear una circunscripción única, sosteniendo la modificación del art. 99.5 de la Constitución para evitar que se repita la situación de las últimas elecciones y no tener que repetir, por tanto, elecciones cada dos meses después de la primera sesión de investidura, si no hay acuerdo entre los partidos para formar un gobierno. Con relación a la corona, defiende que es posible suprimirla mediante el procedimiento de reforma constitucional del art. $168^{15}$, aunque según nuestro criterio, aun admitiendo que esto es posible y constitucionalmente coherente, sería más conveniente proceder, en nuestra opinión, siempre digna de crítica, a un nuevo proceso constituyente. También defiende cambiar la expresión "derecho de gracia" por "indulto" y que este sea motivado ${ }^{16}$. Pero en un Estado de Derecho, creemos, el indulto no tiene razón de ser. Por último, coincidimos con el autor en la necesidad de reforma del propio procedimiento de reforma, lo cual es posible siempre que se mantenga el principio de rigidez, mediante el procedimiento del art. 168, en nuestra Constitución ${ }^{17}$. Sostenemos, además, junto con el autor, que es preciso modificar el art. 167 para hacer obligatorio el referéndum, suprimiendo por innecesario el art. $168^{18}$. Pero ello requiere el establecimiento de unas cláusulas de intangibilidad que, a pesar de ya existir en la Constitución unos límites implícitos vedados al poder ordinario y al poder de reforma constitucional, proporcionarían a la Constitución una mayor protección, aunque somos conscientes que ello debería ser tarea del Poder Constituyente.

En relación a los derechos fundamentales, defiende eliminar cualquier jerarquización entre los mismos, como ya vino sosteniendo desde hace largo tiempo nuestro Maestro

\footnotetext{
${ }^{11}$ Cfr., FONDEVILA MARÓN, M., La reforma constitucional en España...pp. 102 y La disolución de la soberanía en el ámbito estatal..., pp. 390-397.

${ }^{12}$ Cfr., RUIPÉREZ ALAMILlO, J., La Constitución del Estado de las Autonomías..., pp. 55-62.

${ }^{13}$ Cfr., RUIPÉREZ ALAMILlO, J., “¿Podría suprimirse el Senado español mediante la técnica de la reforma constitucional? (Una primera aproximación del problema práctico desde las Ciencias Constitucionales) (I)”, Teoría y Realidad Constitucional, UNED, núm. 34, 2014, pp. 171-183 y “¿Podría suprimirse el Senado español mediante la técnica de la reforma constitucional? (y II), Teoría y Realidad Constitucional, 2015, pp. 145-163.

${ }^{14}$ Cfr., FONDEVILA MARÓN, M., La reforma constitucional en España..., p. 170.

${ }^{15}$ Ibídem, p. 185.

${ }^{16}$ Ibídem, p. 187.

${ }^{17}$ Ibídem, p. 185.

${ }^{18}$ Ibídem, p. 190.
} 
común, Javier Ruipérez Alamillo ${ }^{19}$, concretamente en lo atinente a los derechos sociales $^{20}$. Y es que, como ya han demostrado experiencias del pasado, mantener la consideración de este tipo de derechos en una categoría inferior es un error no sólo de eficacia normativa formal, sino también material. Tomemos como ejemplos al derecho a la educación, recogido en el art. 27 de nuestra Constitución, que es uno de los pocos derechos sociales que goza de la mayor protección en nuestra Constitución, y el derecho a la salud, recogido en el art. 43, mediante un sistema de Seguridad social. Si estos derechos se encuentran recogidos en la Constitución, pero su aplicación depende de que el gobernante de turno estime la necesidad de cumplirlos o no, supone afirmar que existen partes dentro de la Constitución que no forman parte de la consideración de Norma Suprema, lo cual le resta a la misma fuerza vinculante. Incluso aunque la educación pueda ser protegida en amparo, si la misma busca formar operarios y no ciudadanos responsables de un sistema democrático, se estaría vulnerando en parte dicho precepto. Por otra parte, el incumplimiento de los preceptos mencionados conduce inexorablemente a la ineficacia de los derechos a la libertad de expresión y a la dignidad de la persona. Y ello es debido a que es escaso el valor que le va a conferir un individuo a su derecho a la libertad de expresión, recogido en el art. 20, si nadie le ha enseñado mecanismos para pensar racionalmente $\mathrm{y}$ hacer frente a las falacias argumentativas de aquellos que pretendan embaucarlos en negocios perjudiciales a sus intereses o en políticas demagogas o totalitarias. Tampoco su derecho a la dignidad, recogido en el art. 10, tendrá mucho sentido si el individuo se ve obligado a soportar situaciones de miseria por eventualidades a los que todo ser humano está sometido, como la enfermedad o la pérdida de trabajo, viéndose obligado a mendigar y a consentir condiciones de trabajo no sólo precarias, sino incluso, humillantes. Por tanto, mantener dicha distinción en el texto constitucional conlleva a la ineficacia de los derechos fundamentales reconocidos en nuestra Constitución para un no nada desdeñable sector de la población y, con ello, a la pérdida de fuerza normativa de la Norma Fundamental. Ahora bien, como sostiene Fondevila, siguiendo al Maestro, eliminar dicha jerarquía no implica que todos los derechos estén sometidos a la misma protección ${ }^{21}$.

\section{ORIGEN Y DETERMINACIÓN DEL PODER SOBERANO.}

Por ello, es preciso tener en cuenta que la soberanía es un poder fáctico, político e ilimitado, que pertenece al Pueblo, mientras que el poder de reforma es un poder constituido y, por tanto, jurídico y limitado, que corresponda a aquellos órganos que el Poder Constituyente haya designado. No conviene, por razones de espacio, detenerse a definir conceptualmente ambos poderes ni a argumentar la necesidad de separación

\footnotetext{
${ }^{19}$ Cfr., RUIPÉREZ ALAMILLO, J., "El derecho constitucional a la vivienda y la problemática de su arrendamiento en el Estado social (un estudio de Teoría del Estado y de la Constitución como ciencia conceptual y ciencia práctica)", La protección del arrendador como instrumento para dinamizar el mercado de alquiler de viviendas, Dir. Colina Garea, Rafael, Ed. Thomson Reuters, Pamplona, 2014, pp. 65 y 256.

${ }^{20}$ Cfr., FONDEVILA MARÓN, M., La reforma constitucional en España ..., pp. 162-163.

${ }^{21}$ Ibídem, pp. 162-163.
} 
entre los mismos ${ }^{22}$. En cualquier caso es preciso saber que el poder de reforma es un poder constituido, y como tal, se encuentra sometido a la Constitución, salvando la distancia de que mientras que los poderes constituidos están completamente sometidos a todos los preceptos de la Constitución, el poder de reforma sólo lo está parcialmente, es decir, solo debe respetar o bien las cláusulas de intangibilidad, como artículos que designan aquellas materias excluidas de posible reforma, o bien los límites implícitos, como conjunto de principios y valores que definen e identifican una Constitución ${ }^{23}$. Y para que la democracia funcione, los poderes constituidos no deben reformar la Constitución sin respetar los procedimientos que exige la reforma constitucional ni asumir competencias soberanas, al igual que el poder de reforma. Sólo a través del Poder Constituyente, que es aquel que posee el poder soberano, es posible eliminar los límites materiales, es decir, los principios y valores que caracterizan un ordenamiento constitucional y, por tanto, el único capaz de elaborar una nueva Constitución.

Ahora bien, es fundamental analizar en qué consiste la soberanía. Para ello, debemos comenzar formulando la cuestión esgrimida por De la Boëtie ${ }^{24}$, acerca de las razones que llevan a un individuo a consentir la esclavitud civil o política, es decir, a perder su libertad personal o su libertad política, como derecho a someterse a las leyes libremente dadas por sí mismo mediante consenso con el resto de ciudadanos. Ya Hobbes intentó dar respuesta a esta cuestión afirmando que el Estado tiene lugar por el temor que unos homo sapiens se tienen a otros, es decir, cediendo la titularidad de su libertad para asegurar su seguridad. Rousseau por el contrario afirmó que la razón por la que nace el Estado es para asegurar la Libertad, cediendo los individuos el ejercicio de su libertad al conjunto de ciudadanos, del que también forma parte y tiene participación, pero, a diferencia de Hobbes, no su titularidad ${ }^{25}$.

Pero para De la Boëtie, la tiranía nace cuando los seres humanos son sometidos o bien por coacción o bien por engaño. Luego, sus hijos van a someterse a ese poder porque no conocen lo que es vivir libres, haciendo voluntariamente lo que sus predecesores hicieron por coacción. Esta es la primera causa de la tiranía. La segunda deriva de las comodidades, ya que el tirano buscará someter a todos los vicios posibles a sus ciudadanos, para adormecerlos y que así no se preocupen por la pérdida de su libertad. La tercera causa de la tiranía es la búsqueda de legitimidad divina. Pero el principal sostén de la tiranía será contar con una administración jerárquica que se vea favorecida por el apoyo del tirano, de tal modo que la gente favorecida por él sea igual en número a

\footnotetext{
${ }^{22}$ Por comodidad, Cfr., CABANAS VEIGA, M., "La reforma constitucional del 2011 y la Teoría del Poder Constituyente", ADFUDC, $\mathrm{N}^{\circ} 18,2014$, pp. 155-159.

${ }^{23}$ Cfr., DE VEGA GARCÍA, P., La reforma constitucional y la problemática del Poder Constituyente, Ed. Tecnos, Madrid, 2011, pp. 247-251, PÉREZ ROYO, F. J., "La reforma de la constitución". Revista de derecho político, $\mathrm{N}^{\circ} 22,1986$, p. 51 y RUIPÉREZ ALAMILLO, J., El constitucionalismo democrático en los tiempos de la globalización: Reflexiones rousseaunianas en defensa del Estado constitucional democrático y social, Universidad Nacional Autónoma de México, México, 2005, p. 219 y Reforma vs. Revolución..., p. 737

${ }^{24}$ Cfr., DE LA BOËTIE, E., Discurso de la servidumbre voluntaria o el contra Uno (1576), Estudio preliminar, traducción y notas de Hernández Rubio, J. M., $3^{\text {a }}$ Ed., 2007, pp.

${ }^{25}$ Cfr., ROUSSEAU, J.J., El contrato social, (1762), traducido por Enrique López Castellón, Ediciones P. P. P., Madrid, 1985, pp. 66-69
} 
la que resulta perjudicada. De este modo, el tirano esclaviza a sus súbditos a través de otros, especialmente a través de sus soldados. Por ello, el Pueblo odia más a los que sirven al tirano que al tirano mismo. Y ello es lo que fortalece al tirano, ya que éste se debilita cuando se le deja de obedecer ${ }^{26}$.

Sin embargo, tampoco esta definición puede resultar satisfactoria en la medida en que es cuestionable que un poder pueda mantenerse mediante el constante ejercicio de la fuerza sobre los sometidos. Por ello, nos adherimos a la crítica que Heller formula contra Schmitt al entender que ningún poder puede basarse en el mero ejercicio de la fuerza, sino que éste debe contar con algún tipo de normatividad, de algún orden jurídico o moral, que permita hacer efectivas las decisiones ${ }^{27}$. Tampoco entendemos correcto, siempre desde una posición digna de mejora, el razonamiento de Kelsen de entender que el poder deriva de forma descendente desde una Norma Fundamental Hipotética, que da por supuesta, pero que carece de autor, es decir, no fue creada por ninguna voluntad, ya que, siguiendo el principio de las fuentes sociales, no podemos entender que exista ninguna norma al margen de la voluntad humana. Por ello, sólo podremos entender que la pirámide kelseniana es absolutamente válida, útil y coherente si sustituimos la Norma Fundamental Hipotética, carente de voluntad, por los principios éticos políticos, cuyo autor es la propia sociedad. De este modo, el conjunto de normas morales existentes en una sociedad es desorbitante, existiendo un ingente número de principios (la vida, la seguridad, la propiedad...) que se contradicen entre ellos (la pena de muerte atenta contra la vida, pero busca garantizar la seguridad, por seguir con el ejemplo). Por tanto, el detentor del poder político en la sociedad debe optar por aquella contradicción que desee para formular una norma, pero si ésta no se amolda a la voluntad de la sociedad, terminará por ser desobedecida y, finalmente, desaparecerá, debilitando el poder del gobernante.

De este modo es como la normalidad, las normas sociales existentes en la sociedad, condicionan la normatividad, las normas jurídicas ${ }^{28}$. Pero para ejercer ese poder, es preciso respetar los principios políticos éticos de una comunidad política, es decir, respetar los procedimientos de designación y los contenidos morales básicos establecidos en dicha sociedad. De lo contrario, si así no lo hiciese, se entenderá que carece de autoridad para ello y dejará de ser obedecido, al igual que aquellas normas contrarias a la moral de una sociedad. De este modo, si un gobernante se impone por la fuerza en el poder o incumpliendo los mandatos morales de la sociedad que se exigen para ejercer el poder político, éste carecerá de legitimidad, lo que significa que si busca ser obedecido a largo plazo deberá destinar gran parte de sus esfuerzos en convencer a la población de que su gobierno es legítimo. Y de este modo es como también la normatividad puede condicionar la normalidad. Para ello puede, por ejemplo, celebrar banquetes, juegos...o llevar a cabo una potente campaña propagandística. Si no

\footnotetext{
${ }^{26}$ Cfr., DE LA BOËTIE, E., Discurso de la servidumbre voluntaria o el contra Uno (1576), ..., pp. 2055.

27 Cfr., HELlER, H., Teoría del Estado (1934), Traducción por Luís Tobío, Fondo de cultura económica, México, 1985, p. 296.

${ }^{28}$ Ibídem, p. 272.
} 
consigue esta legitimidad, tarde o temprano, su cuerpo de soldados fieles y funcionarios industriosos le darán la espalda, lo que implicará que será privado de cualquier poder.

En las comunidades preestatales, el poder era ejercido por diversas instancias, estando el individuo sometido a las mismas según las diferentes circunstancias. Cada una de ellas (caudillo, druida, ancianos, rey, sacerdote, gremios...) concretaba en normas jurídicas las contradicciones existentes entre las normas morales, optando por una entre las muchas posibilidades. Sin embargo, ello en ocasiones daba lugar a solapamiento de competencias, al entrar a regular situaciones que les afectaban tangencialmente, lo cual acababa dando lugar a antinomias jurídicas insalvables. Ello no fue un problema hasta que el aumento del comercio hizo necesario un aumento de la seguridad jurídica. Sin embargo, ni el sistema feudal, ni ninguno de los sistemas anteriores permitían alcanzar un grado de seguridad jurídica satisfactorio. Por ello, la soberanía es un concepto jurídico nacido por razones políticas ${ }^{29}$, pues el nacimiento del Estado moderno exigía un poder supremo unificado; económicas, pues el comercio huye de allá donde no existe seguridad jurídica; ideológicas, pues se defendía otorgar al monarca un poder absoluto; y personales, pues concretamente ese rey era el de Francia y Bodín era un fiel defensor del mismo, reivindicando de una forma abstracta y genérica los concretos poderes que reclamaba para sí el soberano francés ${ }^{30}$. Y este poder pasó exactamente igual, como un testigo, al Pueblo, con el liberalismo.

Por tanto, nadie debería ignorar, como ya expusimos antes, de que corresponde al conjunto de ciudadanos de la comunidad política la creación de los principios éticospolíticos que otorgan validez a los preceptos emanados de un determinado poder. Esas normas no se crean racionalmente, sino que surgen de la convención derivada de las continuas adaptaciones de los individuos, tanto a su medio natural, como social e internacional. De este modo, la moda no es creada por una persona concreta, sino que todos somos víctimas y verdugos de la misma cuando nos sometemos a sus preceptos. Lo mismo sucede con las lenguas. Evolucionan de acuerdo a los diferentes intercambios culturales que sufra una cultura. Por ello, denominamos comunidad política a aquel conjunto de individuos que participan en la elaboración y ejecución de las normas sociales. Incluso los esclavos, extranjeros y los prisioneros forman parte de la misma. Ésta puede confiar, por convicción o convección, el poder de creación de las normas a una o varias autoridades. Sin embargo, en la Edad Moderna, con el nacimiento de la soberanía, se entiende que la legitimidad, es decir, el ejercicio del poder conforme los principios morales políticos, corresponde o bien al Pueblo o bien a otro órgano, lo que supondría una autocracia.

Así, denominamos Pueblo a la comunidad jurídica, es decir, no como creadora de normas morales, sino como creadora de normas políticas. Ahora dicha comunidad no se limita a crear de forma desregulada las normas morales que la rigen, sino que, tomando conciencia de su propio poder, decide ser ella misma quien, racionalmente, opte por

\footnotetext{
${ }^{29}$ Cfr., JELLINEK, G., Teoría General del Estado, (1911, 2a Edición), Prólogo y traducción de Fernando de los Ríos, Ed. Fondo de Cultura económica, 2000, p. 619.

${ }^{30}$ Cfr., FONDEVILA MARÓN, M., La disolución de la soberanía en el ámbito estatal..., pp. 90-97.
} 
elegir entre las múltiples contradicciones que se dan, dentro de la comunidad, entre los principios políticos, para establecer aquellas normas que debe regir la ejecución de los actos jurídicos de las diversas autoridades; de los poderes ordinarios, en definitiva. Por el contrario, denominamos autócrata no sólo a aquel individuo al que los principios éticos le confieren autoridad para determinar que norma jurídica se aplicará, baremando los diferentes principios morales en conflicto aceptados por la sociedad, sino también puede ser un grupo de personas que, o bien no sean elegidos por el Pueblo, o bien, siéndolo, actúen sólo a favor de sus intereses ${ }^{31}$.Por esta razón, en el siglo XIII ningún gobernante debía acudir a la legitimación popular para justificar su poder, y desde hace más de un siglo cualquier dictador debe hacer verdaderas piruetas retóricas para convencer a sus súbditos de que su poder es democrático. Además, es preciso diferenciar la Nación del pueblo (nótese, con minúscula), como hace Fondevila, pues el primero alude a una unidad cultural mientras que el segundo hace referencia a un sentimiento de pertenencia a una unidad política, tenga o no existencia real ${ }^{32}$.

Pero esa creación y ejecución de los principios políticos éticos no se reducen a una sola comunidad política. También se crean, como es obvio, derivados del contacto entre las diferentes comunidades ${ }^{33}$, lo que explica el nacimiento del Derecho internacional ${ }^{34}$. Y son precisamente los principios políticos éticos que han regido hasta ahora la Comunidad Internacional los que establecen que cada comunidad política decida por sí misma a la autoridad que concrete todas sus normas políticas en unos pocos preceptos. Por ello, sólo podemos entender el Derecho internacional como nacido de los Estados ${ }^{35}$. Por tanto, no podemos dudar de que existen unos principios éticos que rigen las relaciones entre los Estados, de los que se extrae el Derecho internacional. Pero dicha comunidad global carece, al menos por ahora, de un órgano internacional que goce de legitimidad para poder someter a la humanidad entera, ya que la legitimidad continúa siendo estatal. Por ello, Kelsen ${ }^{36}$, creemos, siguiendo la crítica de Heller, desde una perspectiva siempre cuestionable, erraba al otorgar la soberanía al Derecho internacional, ya que éste carece de una instancia que positivice en preceptos jurídicos las normas éticas que rigen a nivel internacional. Sin duda alguna, los principios políticos de cada comunidad política están condicionados por los principios existentes en la comunidad internacional. Por tanto, es la comunidad internacional la que elabora los principios que legitiman el poder en las comunidades políticas que mantienen relaciones internacionales comunes, lo cual favorece el comercio y las conquistas, pero la concreción de esos principios sólo puede corresponder a una autoridad que emane de

\footnotetext{
${ }^{31}$ Cfr., ARISTÓTELES, Política, Traducido por Patricio de Azcárate, Editorial Austral, 2011, pp. 279282.

${ }^{32}$ Cfr., FONDEVILA MARÓN, M., "Pobo, Estado, Nación”, AFDUC, A Coruña, 2011, p. 215.

${ }^{33}$ Cfr., HÖFFE, O., Ciudadano económico, ciudadano del Estado, ciudadano del mundo. Ético Política en la era de la globalización, Traducido por Carlos Díaz Roca, Kazt Editores, 2007, p. 221.

${ }^{34}$ Cfr., HELLER, H., La soberanía: contribución a la teoría del Derecho estatal y del Derecho internacional, Traducción y estudio preliminar de Mario de La Cueva, Fondo de Cultura económica, México, 1995, p. 235.

${ }^{35}$ Ibídem, p. 279.

${ }^{36}$ Cfr., KELSEN, H., Teoría General del Estado, Traducido por Luis Legaz Lacambra, Editorial Comares, 2002, Granada, p. 211.
} 
las diferentes comunidades políticas. Por tanto, la creación de legitimidad es internacional (aunque puede no serlo), pero la creación de soberanía es absolutamente estatal. Y cuando Kelsen le atribuye bienintencionadamente la soberanía al Derecho internacional, la consecuencia inmediata era, en realidad, la eliminación de la misma.

La eliminación del concepto y ejercicio de la soberanía es posible, en tanto en cuanto que se trata de una creación racional humana y, como tal, de una convención. Y la eliminación de dicho concepto implicaría necesariamente también la eliminación de su objeto, es decir, del Estado nacional. Por tanto, eliminar la soberanía no implica ni tan siquiera la desaparición de toda comunidad política. El homo sapiens ha organizado su vida política a través de incontables estructuras políticas en las que no existía la soberanía. Cuestión distinta es si es posible que exista una Democracia, como creación del ordenamiento jurídico y acatamiento del mismo por todos los ciudadanos ${ }^{37}$, sin soberanía. Y es que, partiendo de que toda democracia actual requiere una Constitución que limite a los representantes que formen parte de los poderes constituidos en su actuación, ya que una Asamblea formada por todos los ciudadanos del Estado que buscase la voluntad general no podría jamás limitar la esfera individual de un ciudadano $^{38}$ sin que ello implicase también su supresión para el resto del cuerpo político $^{39}$. Así, dentro de los márgenes establecidos por dicha Asamblea, los órganos constituidos serían quienes deberían ejecutar sus decisiones establecidas mediante sentencias y actos administrativos. Sin embargo, debido a que en la actualidad carecemos de los medios telemáticos para llevar a cabo dicha Asamblea en Estados de extensiones considerables, es preciso que incluso la elaboración de aquel mandato soberano procedente de los ciudadanos se redacte por un pequeño grupo de ciudadanos especializados en la materia y se ratifique, eso sí, por todo el Pueblo mediante plebiscito $^{40}$. Pero ello supone la presunción de que existe un poder supremo con la facultad de alterar sin límite el ordenamiento jurídico que rige la comunidad y, por tanto, presupone el reconocimiento necesario de la soberanía.

\section{LOS SUBTERFUGIOS OLIGÁRQUICOS FRENTE A LA SOBERANÍA POPULAR.}

Así, desde el nacimiento del Estado moderno, a finales del siglo XV y principios del XVI, se entendió que la soberanía era indivisible ${ }^{41}$. Ello implicaba que el poder del

\footnotetext{
${ }^{37}$ Esas son las máximas enunciadas por Maquiavelo. Cfr., DE VEGA GARCÍA, P., "La Democracia como proceso. Algunas reflexiones desde el presente del republicanismo de Maquiavelo", Eds: A. Guerra y J.F. Y otros. Alternativas para el siglo XXI. I Encuentro en Salamanca, Sistema, Madrid, 2003, pp. 469-479 y RUIPÉREZ ALAMILLO, J., El constitucionalismo democrático en los tiempos de la globalización:..., p. 177 y Libertad civil e ideología democrática, Universidad Nacional Autónoma de México, México, 2008, pp. 491-493.

${ }^{38}$ Cfr., FONDEVILA MARÓN, M., "La herencia rousseauniana, en el pensamiento constitucional, 300 años después, $A F D U C, 2012$, p. 375.

${ }^{39}$ Cfr., ROUSSEAU, J.J., El contrato social, (1762), traducido por Enrique López Castellón, Ediciones P. P. P., Madrid, 1985, pp. 143-144.

${ }^{40}$ Cfr., DE VEGA GARCÍA, P., La reforma constitucional y la problemática del Poder Constituyente, Ed. Tecnos, Madrid, 2011, pp. 114-118 y RUIPÉREZ ALAMILLO, J., Reforma vs. Revolución...., pp. 132-133.

${ }^{41}$ Cfr., FONDEVILA MARÓN, M., La disolución de la soberanía en el ámbito estatal.., pp. 84-98.
} 
monarca se hacía absoluto, en detrimento del poder local de los señores feudales ${ }^{42}$. De esta forma, comenzó la defensa, protagonizada por los monarcómanos, derivada de la intolerancia nacida tras el surgimiento del protestantismo, de la limitación del poder del Rey por el Pueblo, entendido como reunión de los tres estamentos, es decir, de los Estados Generales. Para ello, autores como Salisbury ${ }^{43}$, Junius Brutus ${ }^{44}$ o Althusio ${ }^{45}$ van a defender que el poder del Pueblo se encuentra muy por encima del poder del monarca, con la finalidad de recuperar las facultades que le habían sido arrebatadas. Se trataba de un enfrentamiento entre facciones de la clase dominante. Pero la Historia del pensamiento político arrolla aquellos cauces que las ideas han trazado, siguiéndolas, pero modificándolas a su antojo. De este modo, el liberalismo se hace heredero de esta pretensión y comienza a defender que el poder soberano del Pueblo pertenece no a la suma de los votos del estamento noble, el eclesiástico y el popular, sino que, única y exclusivamente corresponde a este último, el popular, que pasa a englobar a los demás. Así es como las ideas engendradas por el feudalismo sirvieron para legitimar su desmantelamiento ${ }^{46}$. Cavaron una trinchera para defenderse contra el monarca absoluto que se acabó convirtiendo en su propia tumba.

De este modo, tras las revoluciones liberales defensoras de la soberanía popular, todo el estamento privilegiado adoptará posiciones absolutistas, a la vista de los desfavorables derroteros que les habían traído la defensa de la soberanía del Pueblo. Pero la legitimación democrática se fue calando paulatinamente en la sociedad occidental, estableciendo límites máximos de avance y retroceso. Por ello, a pesar de los fallidos intentos absolutistas por restaurar el Antiguo Régimen sin alteraciones, debieron resignarse a aceptar, no sin resentimiento, primero la aprobación de las Cartas Otorgadas $^{47}$ por los monarcas, para finalmente desembocar en la monarquía constitucional $^{48}$. De este modo se va a entender que la soberanía puede compartirse entre el monarca y el Parlamento, elegido por el Pueblo. Sin embargo, los notables incumplimientos constitucionales por parte de Rey, al estar éste por encima de la Norma Fundamental, llevaron a los liberales a prescindir del reparto de la soberanía en dos mitades, estableciendo el principio democrático como único legitimador de la soberanía.

Pero una vez que los burgueses, defensores del pensamiento liberal, se consagraron en el poder, abandonaron la defensa de la soberanía popular, entendida como participación

\footnotetext{
${ }^{42}$ Cfr., LASKI, H.J, "La vindiciae en su contexto histórico" en BRUTUS, S. J Vindiciae contra Tyrannos, Traducción por Piedad García-Escudero, Editorial Tecnos, Madrid, 2008, pp. 222-223.

${ }^{43}$ Cfr., DE SALISBURY, J., Policraticus o de las frivolidades de los cortesanos y de los vestigios de los filósofos, Libros I-IV, Traducción por Palacios Royan, José, Servicio de publicaciones e Intercambio científico, Universidad de Málaga, Málaga, 2008, p. 210.

${ }^{44}$ Cfr., BRUTUS, S. J Vindiciae contra Tyrannos, Traducción por Piedad García-Escudero, Editorial Tecnos, Madrid, 2008, p. 154.

${ }^{45}$ Cfr., ALTHUSIUS, J., La política metódicamente concebida e ilustrada con ejemplos sagrados y profanos, Traducido del latín por Primitivo Mariño, Centro de Estudios Constitucionales, Madrid, 1990, p. 579.

${ }^{46}$ Cfr., LASKI, H.J, "La vindiciae en su contexto histórico"..., pp. 226-282.

${ }^{47}$ Cfr., DE VEGA GARCÍA, P., La reforma constitucional y la problemática del Poder Constituyente, Ed. Tecnos, Madrid, 2011, p. 43 y RUIPÉREZ ALAMILlO, J., Reforma vs. Revolución...., p. 38 y El constitucionalismo democrático en los tiempos de la globalización..., pp. 100-120.

${ }^{48}$ Cfr., HELLER, H., Las ideas políticas contemporáneas, Editorial Comares, Granada, 2004, p. 28.
} 
efectiva de los ciudadanos en la vida política, y lo substituyeron por la Nación, como ente abstracto de confusa voluntad, por lo que para expresar la misma era necesario unos representantes que así lo hiciesen ${ }^{49}$. De este modo, los burgueses se convirtieron en los éforos interpretadores de la voluntad de la Nación, el nuevo mito profano. Así, se entendía que la voluntad del Parlamento equivalía a la voluntad de la Nación. Dicha ficción resulta útil si se restringe al ámbito jurídico, pero no si se pretende que sea real $^{50}$. De este modo, mediante el sistema tan poco democrático del sufragio censitario, los burgueses entendían que sus intereses, como era el crecimiento económico y político de sus empresas estaba ligado al crecimiento de la Nación. Y no se equivocaban. Las pretensiones burguesas de colonizar nuevos territorios y de potenciar su crecimiento económico contribuyeron en gran medida al ennoblecimiento de la Nación. Por ello, es absolutamente coherente y necesario que si lo que se busca es el expansionismo económico y militar, es posible que la democracia no sea un buen sistema ${ }^{51}$, en la medida en que pocos ciudadanos democráticos, que por definición son liberales y, por tanto, individualistas, estarían dispuesto a morir por el Estado si sus derechos no corrieran un peligro inminente y efectivo, siempre y cuando, claro está, no exista una fuerte propaganda gubernamental que condicione su voluntad. Por tanto, y sin detenernos demasiado en este tema, no puede existir una democracia allí donde el ciudadano carece de capacidad crítica que le permita defenderse de los engaños procedentes de cualquier tipo de poder. Ahora bien, si lo que buscamos es hacer libres e iguales a los ciudadanos, no cabe duda de que debemos decantarnos por establecer una democracia $^{52}$. En este sistema, por seguir con el ejemplo anterior, si el conjunto de ciudadanos decide poner libremente sus vidas en riesgo y la de sus propios hijos, no será para enriquecer a un particular concretamente o para mejorar la reputación de la Nación, sino sólo para defender su libertad y la de sus descendientes. Es fácil decidir mandar a la guerra a los hijos de otros; lo difícil es mandar a tus propios hijos. Por ello, Pablo Iglesias, fundador del PSOE, defendió en su momento la máxima de "o todos a Cuba o ninguno ${ }^{53}$ ".

Al mismo tiempo, los burgueses locales, hastiados de limitar su poder únicamente al ámbito social y económico de su zona de influencia, decidieron extenderlo también al político. Así, cuando varios individuos fueron conscientes del poder que ejercían en un determinado territorio, pero que éste, a su vez, se veía limitado por un poder central, gobernado por los intereses de una burguesía que utilizaba la política para llevar a cabo sus pretensiones, comenzaron a reivindicar su autonomía. Por ello, es lógico que los burgueses locales encontrasen en la pretensión de independencia el mecanismo más eficaz para liberarse del yugo de la burguesía central, que le impedía actuar con absoluta

\footnotetext{
${ }^{49}$ Cfr., HELLER, H., Las ideas políticas contemporáneas, Editorial Comares, Granada, 2004, p. 28.

50 Cfr., KELSEN, H., Teoría General del Estado, Traducido por Luis Legaz Lacambra, Editorial Comares, 2002, Granada, p. 509.

${ }^{51}$ Cfr., KELSEN, H., "Los fundamentos de la democracia”, Escritos sobre la democracia y el socialismo, Editorial Debate, Madrid, 1988, p. 260.

${ }^{52}$ Ibídem, p. 260.

${ }^{53}$ Cfr., BREY, G., Pablo Iglesias, los socialistas y el movimiento obrero en Galicia (1890-1910), Palacio Municipal de exposiciones Kiosco Alfonso, Mazaira Grafismo S.L., 2001, pp. 28-29.
} 
autonomía. Se trataba, nuevamente, de un enfrentamiento entre dos facciones de la clase dominante. Ejemplo de ello fueron una gran parte de los territorios americanos secesionados. Especialmente lo sucedido en $\mathrm{Cuba}^{54}$. Posteriormente, en la segunda mitad del siglo XIX, se produce el auge del nacionalismo, lo cual no se tradujo necesariamente en independentismo, que tuvo lugar en los territorios sometidos a los antiguos imperios, sino que también dio lugar a la unificación de nuevos Estados, como Alemania e Italia. En Alemania, por ejemplo, los liberales renunciaron a la democracia a favor del monarca prusiano a cambio de lograr una unificación comercial y aduanera que no limitase la libre circulación de capitales y mercancías ${ }^{55}$. Además, ya en 1851, en Francia, con el golpe de Estado de Luis Bonaparte ${ }^{56}$, se había producido un hecho premonitorio en dicho país que, poco después, tendría lugar en toda Europa con el fascismo. En concreto, la antigua aristocracia y la burguesía francesa apoyó y financió a Bonaparte para hacer frente al movimiento obrero, al que, sometiendo o engañando, mantenía en orden, especialmente a la Montaña, el partido socialdemócrata francés.

Una vez más, los intereses nacionalistas se encontraban unidos a los intereses de la burguesía. Este interés desmedido por ampliar el mercado exterior de sus países, manteniendo el proteccionismo en el propio, llevó a lo que todos conocen como Imperialismo. Por lo que nos interesa en estas líneas, ello implicó el sometimiento de los diversos Pueblos de toda África, gran parte de Asía y, de forma económica, de los existentes en Latinoamérica a las metrópolis occidentales. Tras la I Guerra Mundial, derivada de un nacionalismo enfervorizado, aplacado con la sangre de varios millones de vidas humanas, finalmente comenzó a extenderse la idea de autodeterminación de los diferentes Pueblos de la Tierra. Y dicho principio surge unido al principio democrático, como el Derecho de todo Pueblo a decidir los modos y las formas en que debe ser gobernado $^{57}$, el cual comienza a hacerse efectivo en Europa con la Constitución de Weimar de 1919.

Por todo ello, no cabe duda de que este nacionalismo económico es independiente del sentimiento de pertenencia a una comunidad o a una cultura que pueden poseer los diferentes individuos, ya que es innegable la existencia de diferentes Pueblos y su

\footnotetext{
${ }^{54}$ Un ejemplo histórico de la primacía de la libertad económica sobre la dignidad humana la encontramos en 1884, con la emigración de remesas de gallegos a Cuba debido a una epidemia que asoló la región gallega. Así, los gallegos se vieron forzados a firmar unos contratos que no entendían y que establecían férreos sistemas disciplinarios que anulaban su libertad, para poder dar de comer a sus familias, así como el sometimiento a deplorables condiciones de vida, colocándolos en una posición de semiesclavitud. Sin embargo, cuando la cuestión llegó a las Cortes españolas, se produjo una paradoja política que no se debe olvidar: Los abolicionistas defendieron que los contratos celebrados eran absolutamente válidos, ya que habían sido firmados en el uso pleno de la autonomía de la voluntad. Por otro lado, los defensores de la esclavitud se opusieron, al considerar que ningún hombre libre puede verse sometido a las mismas condiciones que un esclavo. Finalmente, por falta de recursos económicos para indemnizar al empresario cubano que promovió la empresa de contratación de gallegos por rescisión del contrato, las Cortes decidieron que los contratos siguieran vigentes. Vid., CAMBRÓN INFANTE, A., "Emigración gallega y esclavitud en Cuba (1854). Un problema de Estado", AFDUC, $\mathrm{N}^{\circ}$ 4, 2000.

${ }_{55}^{55}$ Cfr., HELLER, H., Las ideas políticas contemporáneas, Editorial Comares, Granada, 2004, p. 55.

56 Vid., MARX, K., El 18 brumario de Luis Bonaparte (1869), Fundación Federico Engels, 2003, pp. 132-135.

57 Cfr., RUIPÉREZ AlAmillo, J., El constitucionalismo democrático en los tiempos de la globalización.., pp. 186-191.
} 
derecho a la autodeterminación ${ }^{58}$. Pero cuando dicha defensa implica la supremacía egoísta de los intereses económicos y sociales de cada uno de Pueblos y el abandono de la solidaridad entre los mismos, lo que esconde, en realidad, dicha defensa, es la salvaguardia de los intereses de una sola clase social, que suele ser aquella que tiene interés en la expansión militar hacia otros Pueblos; su explotación económica, en la que el ciudadano de a pie no obtiene beneficio alguno o, en el mejor de los casos, el sometimiento de sus propios ciudadanos cuando, por ejemplo, el poder central se lo impidiese, por estar tomado por fuerzas democráticas. Por tanto, no se trata de rechazar el nacionalismo de cada uno de los Pueblos de la Tierra, sino muy al contrario, salvaguardarlo, para proteger la soberanía de los mismos. Dicha autodeterminación es posible en el seno de otro Estado que salvaguarde de forma efectiva sus identidades lingüísticas, económicas y culturales, evitando discriminación de los territorios, lo que se produciría si se privilegiase a unos y desatendiese a otros. Y ello sólo es posible mediante una representación efectiva de todos los ciudadanos en el órgano central, con independencia de que exista o no un órgano de representación territorial ${ }^{59}$. Lo relevante será, en todo caso, que el órgano central goce de aquellas competencias que requieran una defensa conjunta y fuerte de todo el Estado, mientras que las entidades federadas gocen de aquellas facultades que se administren mejor a nivel local, atendiendo a las particularidades económicas, sociales y culturales de cada zona.

Por ello, la autodeterminación supone que cada Pueblo debe tener un Estado que lo represente y no al que estar sometido. Por tanto, ésta tendrá lugar cuando los ciudadanos de ese Pueblo elijan, libremente, conformarse como un único Estado o, también, cuando en el ejercicio de su legítimo derecho, optan por constituir un Estado con otros muchos Pueblos $^{60}$. De esta forma, el derecho de autodeterminación de los Pueblos enlaza directamente con los principios éticos políticos que rigen a nivel internacional, sobre los que se sustenta la soberanía de cada Pueblo. De esta forma, un Pueblo sentirá que está legítimamente gobernado tanto si ha sido el conjunto de sus ciudadanos los que han elegido formar parte de un Estado más amplio que su territorio, cuyo poder y normas fundacionales verá como legítimas, como cuando decide darse sus propias normas constitucionales.

Al mismo tiempo que terminaba la I Guerra Mundial, el comunismo se encontraba en su mayor auge, por lo que la burguesía, a nivel internacional, encontró en él a un enemigo común que combatir antes de proseguir sus encarnizadas batallas. Además, debido a la consolidación del sufragio universal, a través del cual las clases populares podían hacer efectivas sus demandas sociales y políticas, una parte de los burgueses europeos comenzaron a acercarse a posturas autoritarias, como el fascismo. De este modo, los principios de Libertad, Igualdad y Fraternidad, entonados en su momento para abanderar las revoluciones liberales, fue abandonada por sus portaestandartes burgueses

\footnotetext{
${ }^{58}$ Cfr., FONDEVILA MARÓN, M., "Pobo, Estado, Nación”, AFDUC, A Coruña, 2011, p. 216.

${ }^{59}$ Cfr., RUIPÉREZ ALAMILlO, J., “¿Podría suprimirse el Senado español mediante la técnica de la reforma constitucional? (Una primera aproximación del problema práctico desde las Ciencias Constitucionales)", Teoría y Realidad Constitucional, UNED, núm. 34, 2014, pp. 195-200.

${ }^{60}$ Cfr., FONDEVILA MARÓN, M., "Pobo, Estado, Nación”, AFDUC, A Coruña, 2011, p. 216.
} 
cuando estos pasaron de ser mera retórica y epopeya histórica al plano político, jurídico y real. Así, se puso de manifiesto que la defensa de la democracia liberal era un ardid burgués para poder llevar a cabo sus intereses, y cuando estos se ponían en cuestión a través del propio sistema democrático, preferían volver a posturas autoritarias. De este modo, al igual que los señores feudales en su momento apoyaron el poder popular para favorecer sus intereses, acercándose a posturas autoritarias cuando éstos se encontraban en peligro, los burgueses procedieron de forma idéntica. Pero esa bandera fue recogida, como si de un testigo se tratase, por la socialdemocracia, la cual venía a conjugar los intereses de la pequeña y mediana burguesía, defensora de la democracia, con la clase obrera que, a cambio del pleno reconocimiento de sus derechos sociales y económicos, aceptaba los modos liberales de Constitución y representación parlamentaria. Ello condujo a que, en la II Guerra Mundial, el mundo se dividiese entre fascismos y democracias y, como es bien sabido, a otra guerra mundial. Pero esta vez no se trataba de los intereses nacionales de las respectivas clases dominantes, sino la lucha de dos concepciones políticas del mundo, representadas por las respectivas clases sociales que buscaban adeptos en el conjunto de ciudadanos, con la finalidad de que se adhiriesen a su causa.

Tras la II Guerra Mundial, comienza la descolonización y la guerra fría, y con ello, la lucha por la hegemonía del mundo entero. Esta vez, se trataba de la lucha de una burguesía internacional que había aceptado, por convicción o por coacción, la democracia formal, contra un grupo de intelectuales que le disputaban el poder sobre el mundo entero, con un sistema, en principio, totalitario. Ambos bandos aleccionaban a las masas para luchar contra un orden político, social y económico que entendían como ineficaz e injusto. El capitalismo, para hacer frente a su enemigo natural, decidió abrazar la socialdemocracia, sistema alabado por obreros y burgueses, y lo puso en funcionamiento. Ello tuvo los éxitos esperados: la creación de una democracia social daría lugar a una clase media mayoritaria que permitirá conciliar los diferentes intereses antagónicos, como en su momento afirmara Aristóteles ${ }^{61}$. Al mismo tiempo, el derecho de autodeterminación de los pueblos se iba haciendo efectivo, lo que fue aprovechado por la URSS y por el bloque capitalista para aumentar su influencia. Sin embargo, existieron una serie de países que decidieron no alinearse a ninguno.

Finalizada la guerra fría, el poder económico multinacional comenzó a defender que los Estados nacionales estaban obsoletos, al igual que el Estado social ${ }^{62}$, ya que no respondía a los intereses globalizadores ${ }^{63}$. Ello derivó de la defensa corporativa nacida durante la II Guerra Mundial que unió a los capitalistas de todo el mundo contra los comunistas, y viendo sus buenos resultados, decidieron seguir ejerciendo ese poder de

\footnotetext{
${ }^{61}$ Cfr., ARISTÓTELES, Política, Traducido por Patricio de Azcárate, Editorial Austral, 2011, p. 219.

${ }^{62}$ Thatcher famosamente declaro -en su primera reunión con los que serían sus ministros de oposición"Esto es lo que creemos" al mismo tiempo que puso sobre la mesa una copia de la famosa obra de Hayek "Camino de servidumbre".

${ }^{63}$ Cfr., RUIPÉREZ AlAMiLlo, J., El constitucionalismo democrático en los tiempos de la globalización..., pp. 146-147 y RUIPÉREZ ALAMILLO, J., "Estado social versus aldea global", Congreso Internacional sobre culturas y sistemas jurídicos comparados. Mesa X "Metodología del Derecho comparado: Derecho comparado y procesos de integración", p. 77.
} 
manera indefinida. De este modo, aparecen múltiples organizaciones internacionales cuyo objetivo era garantizar el libre mercado internacional, lo cual evitaría caer en las políticas proteccionistas de antaño. Al mismo tiempo, comenzó la defensa de la gobernanza como sistema de gobierno, frente a las democracias nacionales. Podemos definir la Gobernanza ${ }^{64}$, neocorporativismo o consociacionismo, como una negociación del sector público con el sector privado (económico y social), buscando alcanzar un consenso, frente a la obsoleta imposición jerárquica del poder político ${ }^{65}$. Se trata, pues, de una cooperación multinivel ${ }^{66}$, tanto vertical (entre las diferentes escalas políticas) como horizontal (entre los distintos territorios) ${ }^{67}$ tratando de solucionar el mal funcionamiento del sistema político ${ }^{68}$. Esto se traduce en un "governing without goverment $^{69}$ ". Supone un acuerdo con las diferentes fuerzas sociales por parte del Estado, lo que erosiona el poder de los órganos estatales. Se sostiene con él la ideología tecnocrática de la lógica, rechazando la ideología y la política y defendiendo la estabilidad y el crecimiento, por lo que se desconfía de las políticas redistributivas. Además, se crean monopolios de representación y sus procesos carecen de

\footnotetext{
${ }^{64}$ El Libro blanco sobre la Gobernanza en Europa, 2001, la define como "la capacidad de las sociedades para dotarse de sistemas de representación, de instituciones, de procesos y de cuerpos sociales, como instrumento de control democrático, de participación de las decisiones y de responsabilidad colectiva. Ante semejante definición, cualquier constitucionalista podría entender que la gobernanza equivale a soberanía. Al hablar de ese derecho de los ciudadanos de decidir los modos y formas en que quieren ser gobernados se estaría aludiendo claramente al Poder Constituyente.

${ }^{65}$ Cfr., FARINÓS DASÍ, J., y VICENT BOIRA MAIQUES, J., "Escenarios, visións, Estratexias e o debate metropolitano", Áreas Metropolitanas galegas, Coordinador X. M. Souto González, Ed. Xunta de Galicia, Capítulo I, 2009, pp. 51 y 64, MARQUES DA COSTA, E., "Características xeográficas e Transformacións recentes das áreas metropolitanas de Lisboa e O Porto", Áreas Metropolitanas galegas, Coordinador X. M. Souto González, Ed. Xunta de Galicia, 2009, Capítulo I, pp. 159, 161 y 184.SORRIBES I MONRABAL, J., QUINTÁS ALONSO J., y DEL ROMERO RENAU, L., "Da extratexia territorialás ás boas prácticas das áreas metropolitanas”Áreas Metropolitanas galegas, Coordinador X. M. Souto González, Ed. Xunta de Galicia, 2009, Capítulo V, pp. 87-92, PAZOS OTÓN, M." "As Áreas Metropolitanas en Galicia: Aproximación dende a movilidade, a demografía e a gobernanza", Áreas Metropolitanas galegas, Coordinador X. M. Souto González, Ed. Xunta de Galicia, 2009, Capítulo V, p. 325 y VÁZQUEZ BARQUERO, A. con SEISDEDOS, G. y CRUZ LACALLE, M., Las regiones policéntricas, territorio estratégico del desarrollo económico, Centro de Estudios en Desarrollo de la Universidad Autónoma de Madrid, Xunta de Galicia, 2009, pp. 11-12.

${ }^{66}$ De acuerdo con este concepto, esta cooperación se da en una dimensión internacional, supranacional e infranacional. Cfr., WEILER, J. H. H., con HALTERN, U.R., y MAYER, F. C., "La Democracia europea y sus críticos: cinco problemas", Problemas de legitimación en la Europa de la Unión. Las respuestas del Tratado de Amsterdan, coordinador T. de la Quadra-Salcedo y A. Estela de Noriega, Universidad Carlos III de Madrid, Boletín Oficial del Estado, Madrid, 2000, pp. 67-68.

${ }^{67}$ Cfr., FARINÓS DASÍ, J., y VICENT BOIRA MAIQUES, J., "Escenarios, visións, Estratexias e o debate metropolitano"..., pp. 58-60, SOUTO GONZÁLEZ, X. M., "Conclusións" Áreas Metropolitanas galegas, Coordinador X. M. Souto González, Ed. Xunta de Galicia, 2009, p. 485-487 y VÁZQUEZ BARQUERO, A. con SEISDEDOS, G. y CRUZ LACALLE, M., Las regiones policéntricas..., pp. 151, $159-161$ y 182.

${ }^{68}$ Como la corrupción, los favoritismos o los intereses partidistas. Cfr., FARINÓS DASÍ, J., y VICENT BOIRA MAIQUES, J., "Escenarios, visións, Estratexias e o debate metropolitano"..., pp. 60,63 у 73, SORRIBES I MONRABAL, J., QUINTÁS ALONSO, J., y DEL ROMERO RENAU, L., "Da extratexia territorial...", pp. 85 y 129-134 y VÁZQUEZ BARQUERO, A. con SEISDEDOS, G. y CRUZ LACALLE, M., Las regiones policéntricas..., pp. 49, 90, 109, 152-163. Se considera, incluso, un sistema de gestión que está llamado a sustituir al viejo sistema administrativo por la eficiencia que se obtiene con su aplicación.

${ }^{69}$ Cfr., SORRIBES I MONRABAL, J., QUINTÁS ALONSO J., y DEL ROMERO RENAU, L., "Da extratexia territorial...”, p. 85. Esto recuerda a la idea de Rousseau de Gobierno sin gobierno.
} 
transparencia ${ }^{70}$. Busca sustituir el consenso por la regla de las mayorías, siendo las élites quienes deben comprometer los segmentos de la sociedad que representan. Así, se reduce la transparencia y sirve como freno a la democratización interna que debilita a las élites representantes, lo que posibilita que se desarrolle mejor la labor de representación que, al carecer de frenos, se transforma en autocrática. También impide la aparición de nuevas minorías que no formen parte del cártel, pues ello debilita, según Weiler, Haltern, y Mayer, un gobierno democrático ${ }^{71}$. Algunos autores consideran, incluso, que sustituirá al sistema administrativo y político tradicional ${ }^{72}$. Sin embargo, algunos problemas de esta forma de gestión son la falta de legitimidad democrática, ya que muchos de sus representantes no son electos ${ }^{73}$. De esta forma, se defiende que la participación política retrasa la toma de decisiones sin que ello redunde en mayor eficacia política ${ }^{74}$. Así, defienden que "La gobernanza se ha consolidado como uno de los nuevos principios rectores y en parte es la respuesta lógica al exceso de burocracia, a la preeminencia del poder político y al déficit democrático criticado en las viejas fórmulas ${ }^{75}$ " pues "conecta las formas tradicionales de gobierno con aquellas más modernas ${ }^{76}$ ". De este modo, los mercados internacionales, como nombre menos político que burguesía internacional, encuentran de nuevo un subterfugio para imponerse por encima de la democracia, dado que el fascismo fracasó.

En este contexto, la globalización ${ }^{77}$ y las nuevas formas de organización territorial han dado lugar a la pérdida de respeto por las fronteras políticas y administrativas, por lo que las fronteras de los municipios, provincias, regiones y naciones se van a ver desbordadas por estas nuevas formas de organización territorial. Por ello, la división

\footnotetext{
${ }^{70}$ Cfr., WEILER, J.H., HALTERN, U.R. y MAYER, F.C., "La Democracia europea y sus críticos...", p. 78.

${ }^{71}$ Ibídem, pp. 75-76.

${ }^{72}$ Cfr., SOUTO GÓNZALEZ, X. M.,“Conclusións”..., pp. 488-489 y VÁZQUEZ BARQUERO, A. con SEISDEDOS, G. y CRUZ LACALLE, M., Las regiones policéntricas ..., p. 90 y 161.

${ }^{73} \mathrm{Si}$ realmente se trata de una simple gestión no necesitaría de una legitimidad democrática. El problema es que la gobernanza va más allá de una simple gestión. Por tanto, es menos democrática que la Democracia. Cfr., SORRIBES I MONRABAL, J., QUINTÁS ALONSO J., y DEL ROMERO RENAU, L., "Da extratexia territorial...", pp. 45 y 85.

${ }^{74}$ Cfr., FARINÓS DASÍ, J., y VICENT BOIRA MAIQUES, J., "Escenarios, visións, Estratexias e o debate metropolitano"..., pp. 65-66.

${ }^{75}$ Cfr., VÁZQUEZ BARQUERO, A., con SEISDEDOS, G., y CRUZ LACALLE, M., Las regiones policéntricas..., p.162 y FARINÓS DASÍ, J., y VICENT BOIRA MAIQUES, J., "Escenarios, visións, Estratexias e o debate metropolitano"..., p. 85.

76 VÁZQUEZ BARQUERO, A., con SEISDEDOS, G., y CRUZ LACALLE, M., Las regiones policéntricas..., cit., p. 182.

${ }^{77}$ Held proporciona una aproximación al concepto de globalización definiéndola como "un proceso (o conjunto de procesos) que constituye una transformación de la organización espacial de las relaciones y transacciones sociales -interpretada en términos de su extensión, intensidad, velocidad e impacto- que genera flujos y redes transcontinentales o interregionales de actividad, interacción y ejercicio de poder". Citado por, ZIMMERLING, R., "Globalización y Democracia: un marco para la discusión", Quórum:Revista de pensamiento iberoamericano, 2003, cit., p. 64. Es un proceso que tiene su origen en la liberalización de los mercados internacionales, la deslocalización de las empresas y el desarrollo de las nuevas tecnologías de la información y las telecomunicaciones. Como consecuencia, ha aparecido un nuevo orden mundial en el que aparecieron nuevos países muy competitivos que buscan cotas de poder y una nueva división internacional del trabajo, derivada de la deslocalización de las empresas.
} 
territorial decimonónica será vista por algunos autores como obsoleta ${ }^{78}$, defendiéndose un modelo que ha de adaptarse al ritmo de las empresas multinacionales ${ }^{79}$. Así, las ciudades han de pasar de prestar servicios a los ciudadanos a prestar servicios a las empresas multinacionales ${ }^{80}$, ya que estas van a buscan mejorar el territorio en el que se encuentran a través de la gobernanza ${ }^{81}$.

Por tanto, las tendencias globalizadoras, tecnocráticas o neoliberales van a ver el territorio no como algo homogéneo, plano, sino con forma de sierra, donde existen territorios prósperos y territorios estancados, para, finalmente, centrar toda la atención económica en los primeros. De esta forma, se ha pasado de un modelo centro-periferia a un modelo policentrista ${ }^{82}$, en el que se apuesta por una flexibilización del territorio ${ }^{83}$, descentralización de las decisiones políticas $^{84}$ y por una menor participación democrática $^{85}$, ya que ésta retrasa las decisiones ${ }^{86}$ y no supone ninguna eficacia política $^{87}$. Además, ante la crisis actual ${ }^{88}$ se defiende que es preciso pensar en términos

${ }^{78}$ Cfr., FARINÓS DASÍ, J., y VICENT BOIRA MAIQUES, J., "Escenarios, visións, Estratexias e o debate metropolitano"..., pp. 28-29 y 31, SOUTO GONZÁLEZ, X. M. "Introdución Segunda Parte", Áreas Metropolitanas galegas, Coordinador X. M. Souto González, Ed. Xunta de Galicia, 2009, pp. 215 y 257-258, PAZOS OTÓN, M., "As Áreas Metropolitanas en Galicia: Aproximación dende a movilidade, a demografía e a gobernanza", Áreas Metropolitanas galegas, Coordinador X. M. Souto González, Ed. Xunta de Galicia, 2009, Capítulo V, p. 326 y 380-381 y SOUTO GONZÁLEZ, X. M., "Conclusións", Áreas Metropolitanas galegas, Coordinador X. M. Souto González, Ed. Xunta de Galicia, 2009, pp. 472-474.

${ }^{79}$ Cfr., FARINÓS DASÍ, J., y VICENT BOIRA MAIQUES, J., "Escenarios, visións, Estratexias e o debate metropolitano"..., p. 53.

${ }^{80}$ Cfr., VÁZQUEZ BARQUERO, A., con SEISDEDOS, G., y CRUZ LACALLE, M., Las regiones policéntricas..., p. 74 y 157.

${ }^{81}$ Cfr., FARINÓS DASÍ, J., y VICENT BOIRA MAIQUES, J., "Escenarios, visións, Estratexias e o debate metropolitano"..., pp. 116-117.

${ }^{82}$ Se defiende que lo relevante no es la situación geográfica, sino cómo decidan relacionarse las ciudades para lograr el desarrollo. Cfr., FARINÓS DASÍ, J., y VICENT BOIRA MAIQUES, J., "Escenarios, visións, Estratexias e o debate metropolitano..., p. 37, BARATA SALGUEIRO, T., y MARQUES DA COSTA, E., "Características xeográficas e Transformacións recentes das áreas metropolitanas de Lisboa e O Porto", Áreas Metropolitanas galegas, Coordinador X. M. Souto González, Ed. Xunta de Galicia, 2009, Capítulo I, p. 233 y VÁZQUEZ BARQUERO, A., con SEISDEDOS, G., y CRUZ LACALLE, M., Las regiones policéntricas..., pp. 7, 11, 67, 69, 79, 109 y 156.

${ }^{83}$ Cfr., FARINÓS DASÍ, J., y VICENT BOIRA MAIQUES, J., "Escenarios, visións, Estratexias e o debate metropolitano"..., p. 67, SOUTO GONZÁLEZ, X. M., "Conclusións"..., pp. 471-472 y 487.

${ }^{84}$ Cfr., VÁZQUEZ BARQUERO, A., con SEISDEDOS, G., y CRUZ LACALLE, M., Las regiones policéntricas..., pp. 43-44 y 58-59 y 152-153.

${ }^{85}$ No todos los autores defensores de las áreas metropolitanas están de acuerdo con esto. Así, algunos autores consideran que la cohesión social no ha de ser un simple principio formal, por lo que la ordenación del territorio deberá dirigirse siempre a tal fin, contando con la participación ciudadana. Así, para éstos, ordenar al territorio no puede dirigirse a favorecer a los territorios más desarrollados y marginar a los territorios estancados. Cfr., MARQUES R. J. y CIDRAIS, A., "Ordenamento do territorio e Goberno das áreas urbanas en Portugal", Áreas Metropolitanas galegas, Coordinador X. M. Souto González, Ed. Xunta de Galicia, 2009, Capítulo III, pp. 157-184.

${ }^{86}$ Éste es el pensamiento de la clase globalizadora. En este sentido, Cfr., RUIPÉREZ ALAMILLO, J., El constitucionalismo democrático en los tiempos de la globalización..., Universidad Nacional Autónoma de México, México, 2005, pp. 190-194.

${ }^{87}$ Cfr., FARINÓS DASÍ, J., y VICENT BOIRA MAIQUES, J., "Escenarios, visións, Estratexias e o debate metropolitano"..., pp. 65-66, SORRIBES I MONRABAL, J., QUINTÁS ALONSO J. y DEL ROMERO, RENAU, L., "Da extratexia territorial...", p. 103 y VÁZQUEZ BARQUERO, A., con SEISDEDOS, G., y CRUZ LACALLE, M., Las regiones policéntricas..., pp. 153-154 y 158-161. 
de eficiencia y eficacia industrial y económica ${ }^{89}$, prescindiendo de modelos territoriales ineficaces y obsoletos. Al mismo tiempo, los ciudadanos no deben sentirse identificados por un orgullo de pertenencia a un territorio o a una cultura, sino que su unión deben radicar en lazos que permitan expandir las ciudades hacia potenciales mercados ${ }^{90}$. Por ello, el Estado Nación debe desaparecer ${ }^{91}$, debiendo quedar fragmentado en comunidades mucho menores que permitan una mayor gobernabilidad, es decir, una menor democracia.

Ante la crisis actual, muchos Estados han optado por establecer políticas proteccionistas, renunciando a pertenecer a instituciones internacionales que antaño les permitían llevar a cabo una economía de libre mercado. Al mismo tiempo, algunos partidos secesionistas, especialmente vinculados a la derecha, han optado por la defensa del independentismo para proteger sus intereses, al tiempo que buscan, aunque cuestionablemente lo puedan lograr, proteger su economía de la invasión de Pueblos vecinos. Lo que es más sorprendente es que los partidos de izquierda también se hayan decantado por el independentismo, defendiendo el reparto de riqueza personal, pero no el territorial, lo cual no podría tener cabida en ningún partido que se considerase ya no sólo socialdemócrata, sino mucho menos aquel que se llame a sí mismo antisistema. Y para ello, han optado por la defensa de la reforma constitucional ${ }^{92}$, en lugar de la defensa de un nuevo Poder Constituyente ${ }^{93}$. Con ello ponen de manifiesto que lo que buscan no es la autodeterminación de su propio Pueblo, sino someterlo a sus intereses ${ }^{94}$.

Por ello, será preciso determinar si un Pueblo independiente es más autodeterminado que un Pueblo que forma parte de un Estado. Pensemos en un gran Estado que antaño fue un imperio constituido a través de la fuerza de la clase nobiliaria. En estos momentos, ese territorio está constituido por diferentes provincias que gozan de autonomía propia, de libertad política y de medios para desarrollar su cultura. Sin embargo, una de las provincias, manifiesta su deseo de independizarse. Ello se debe a que las viejas rencillas del pasado, acerca de las minusvaloraciones culturales sobre los diferentes pueblos por el poder central del antiguo imperio, continúan candentes. En virtud de su derecho a la autodeterminación, esa provincia acaba declarándose

\footnotetext{
${ }^{88}$ Para una mejor comprensión de las causas y consecuencias de la crisis actual Cfr., VÁZQUEZ BARQUERO, A., con SEISDEDOS, G., y CRUZ LACALLE, M., Las regiones policéntricas ..., p. 34-40. Estos autores no ven la crisis como la caída o la interrupción de la globalización, sino que, para él, la crisis supone una reestructuración del mercado internacional que da lugar a un policentrismo internacional en el que ganarán terreno algunos países emergentes.

${ }^{89}$ Cfr., RODRÍGUEZ ÁLVAREZ, J. M., "Estructura institucional y organización local en España: fragmentación municipal, asociacionismo confuso, grandes ciudades y provincias supervivientes", Política y Sociedad, 2010. Vol. 47 Núm. 3p. 90.

${ }^{90}$ Cfr., VÁZQUEZ BARQUERO, A. con SEISDEDOS, G. y CRUZ LACALle, M., Las regiones policéntricas..., p. 125.

${ }^{91}$ Cfr., ZIMMERLING, R., "Globalización y Democracia...", p. 69.

${ }^{92}$ Cfr., FONDEVILA MARÓN, M., "Reforma constitucional y forma territorial del Estado", Teoría y Realidad Constitucional, UNED, 2014, pp. 592-595.

${ }^{93}$ Cfr., FONDEVILA MARÓN, M., "Derecho a decidir y soberanía. A propósito de la STC 42, 2014, de 25 de marzo", TRC., núm. 34, 2014, pp. 603-608.

${ }^{94}$ Cfr., RUIPÉREZ ALAMILLO, J., "La nueva reivindicación de la secesión de Cataluña en el contexto normativo de la Constitución española de 1978 y el Tratado de Lisboa", Teoría y Realidad Constitucional, núm. 31, 2013, pp. 83 y 120-128.
} 
independiente. Los restantes pueblos del antiguo imperio deciden constituirse como un Estado federal. En su constitución acuerdan una solidaridad plena de los territorios, llevando a cabo un eficaz reparto territorial de la riqueza y una defensa conjunta de sus intereses.

Cuando llegan las multinacionales, el nuevo Estado federal imponía unos fuertes tributos para costear el Estado social de sus ciudadanos, pero debido a la fuerza internacional que representaba, al abarcar un enorme territorio y un buen número de personas, consigue acuerdos comerciales que hace atractivo al nuevo Estado federal, a pesar de los elevados impuestos. Las empresas industriales se sitúan en el norte por la abundancia de materias primas, lo que produce un fuerte crecimiento económico en dichos territorios. El excedente tributario obtenido de dicho crecimiento se destina a fomentar empresas manufactureras de productos agropecuarios, cuya riqueza reside en el sur. Ello permite que la totalidad del territorio del Estado se haga atractivo y que los ciudadanos puedan ver garantizados sus servicios sociales. Los diferentes pueblos ven garantizado no sólo su cultura e identidad, sino que la soberanía de cada uno de los pueblos se asegura mediante una efectiva participación de los mismos en los sistemas de representación, que se traduce en solidaridad territorial. De este modo, los ciudadanos de cada uno de los pueblos ven garantizados sus intereses vitales y culturales, pudiendo ver como su libertad política prima sobre los intereses particulares de las empresas multinacionales ${ }^{95}$.

Por la contra, la vieja provincia convertida en Estado, al carecer del mismo peso internacional, a pesar de ser uno de los territorios más potentes del viejo imperio, no puede establecer acuerdos ventajosos, por lo que las multinacionales le imponen unas fuertes condiciones. Al principio se niegan, pero al representar tan poca fuerza, se ven obligados a ceder. Ello implica reducir los impuestos, lo que impide costear unos servicios sociales de calidad, dar impunidad a la contaminación y bajar los derechos laborales. Los ciudadanos del nuevo Estado carecen de soberanía, ya que los que realmente deciden son las multinacionales. Su tierra ha sido contaminada y su cultura ha sido difuminada ante los intereses globalizadores. Ellos han perdido calidad de vida, pero su clase alta, defensora de la independencia, ha mejorado en gran medida su calidad de vida. ¿Realmente podemos afirmar que este pueblo se ha autodeterminado?

\section{CONCLUSIONES.}

La elección del órgano que ejercita la soberanía es una decisión ideológica, pero ello no implica necesariamente que su destrucción implique la neutralidad ideológica ni del aparato político. Muy al contrario, la abolición de la soberanía supone elegir entre diversos sistemas autoritarios u oligárquicos caracterizados por un reparto horizontal del poder. Eliminar la soberanía se traduciría, inevitablemente, en la existencia de varias instancias políticas que elaborarían las normas del rango más elevado del ordenamiento jurídico, como en el feudalismo, o bien mediante convenio entre las mismas o bien

\footnotetext{
${ }^{95}$ Cfr. FONDEVILA MARÓN, M., "Soberanía y globalización”, Constitución y globalización, 2013, pp. 280-290.
} 
solapándose y contradiciéndose y, por tanto, produciendo inseguridad jurídica. Dadas las circunstancias, el Pueblo sería, en el mejor de los casos, una variable más en esta ecuación política que elaborase las normas fundamentales de las comunidades políticas, debiendo negociar con las restantes. Y ante esta situación, carecería de sentido hablar de una verdadera democracia. Por tanto, cuando se busca usurpar las funciones del Pueblo o eliminar su soberanía, en realidad lo que se busca es establecer dictaduras más o menos encubiertas. Y es cuestionable que Pueblo alguno del planeta acepte una dictadura como principio legitimador del poder.

Además, y por todo lo analizado, cabe recomendar una pausada lectura, tanto de su nueva obra como de toda su producción bibliográfica, a todo aquel lector que se interese por la problemática de la soberanía, la autodeterminación y la reforma constitucional en nuestro país. Y es que, en definitiva, se trata de una producción bibliográfica completa que permite obtener una comprensión clara y diáfana acerca de las confusiones que existen acerca de los límites de la reforma constitucional y la relación que existe entre soberanía y autodeterminación, imprescindible para ofrecer a la democracia la necesaria protección que la misma requiere, frente a posibles distorsiones, intencionadas o no, de los poderes políticos y fácticos. Así, el autor demostró con todo su compendio que, una vez más, la pretensión de hacer investigaciones de calidad que persigue cualquier constitucionalista es una labor que ha cumplido de forma indiscutible, por lo que no resulta, en absoluto, temerario augurarle una más que dilatada y provechosa carrera académica. Sin más, y para finalizar, me resta felicitar al autor por su sobresaliente última obra y requerirle para que, en un futuro, nos brinde otra investigación de idéntico calibre. 